SISTEMA
ELETRÔNICO
DE REVISTAS
SER I UFPR

\title{
Desafios para a construção do conceito afrocentrado de desenvolvimento em comunidades quilombolas no Brasil
}

\section{Challenges for construction of the afrocentrated concept of development in Quilombolas communities in Brazil}

\author{
Roberto dos Santos LACERDA ${ }^{1 *}$, Gicélia Mendes da SILVA ${ }^{1}$ \\ ${ }^{1}$ Programa de Pós-Graduação em Desenvolvimento e Meio Ambiente, Universidade Federal de Sergipe (UFS), São Cristóvão, SE, Brasil. \\ *E-mail de contato: robertosl3@hotmail.com
}

Ensaio recebido em 21 de setembro de 2016, versão final aceita em 28 de janeiro de 2018.

RESUMO: No Brasil, as iniquidades sociais persistem ao longo do tempo e estão fortemente associadas ao processo cruel de colonização estruturado no sistema escravocrata. O modelo convencional de desenvolvimento no Brasil, baseado na busca do crescimento econômico em detrimento do equilíbrio socioambiental, tem sido extremamente danoso às comunidades tradicionais, que têm seus territórios e as riquezas naturais existentes ameaçados frente à lógica ocidental de progresso. As comunidades quilombolas têm lutado ao longo dos anos para efetivar seus direitos de cidadania, principalmente o de titulação dos seus territórios, bem como o de acesso às políticas públicas de saúde, educação, e demais direitos de bem-estar social. Diante do discurso de desenvolvimento sustentável, inicialmente utilizado para promover a integração dos países e comunidades periféricos na lógica desenvolvimentista dos países centrais, as comunidades tradicionais quilombolas não têm suas necessidades e particularidades contempladas em propostas e projetos. Apesar de divulgarem a necessidade de equilíbrio econômico, social e ambiental, os agentes governamentais indutores de políticas de desenvolvimento sustentável não estimulam a emancipação das comunidades. Tampouco incentivam a valorização das concepções e valores civilizatórios que positivamente têm integrado as comunidades aos seus territórios, de modo a promover o convívio equilibrado entre seus membros e o meio ambiente. A construção de um novo panorama para promoção do bem-estar coletivo e da conservação ambiental em comunidades quilombolas requer o reconhecimento da contribuição de epistemologias que localizem o afrodescendente no centro da sua história e de seu presente, promovendo a descolonização do pensamento. A discussão acerca do desenvolvimento em comunidades quilombolas perpassa pelo reconhecimento, pela efetivação dos direitos das comunidades e pela valorização dos saberes e práticas das comunidades, na construção de ambientes sustentáveis e equânimes.

Palavras-chave: quilombos; desenvolvimento; território; sustentabilidade. 
ABSTRACT: In Brazil, social inequities persist over time and are strongly associated with the cruel process of colonization structured in the slave system. The conventional model of development in Brazil, which is based on the pursuit of economic growth at the expense of social and environmental balance, has been extremely harmful to the traditional communities who have their territories and natural wealth threatened when facing the Western logic of progress. Quilombola communities have struggled over the years to effectuate their citizenship rights, especially the titling of their territories as well as the access to public health policies, to education and to other social rights. Given the sustainable development discourse originally utilized to promote the integration of peripheral countries and communities in the developmental logic of the central countries, the quilombola communities do not have their needs and particularities met in proposals and projects. Despite spreading the need for economic, social and environmental balance, government agents who are inductors of sustainable development policies neither encourage the empowerment of communities nor appreciate the ideas and civilizing values that have positively integrated communities to their territories, promoting balanced interaction between their members and the environment. The construction of a new perspective to promote the collective welfare and environmental conservation in quilombola communities requires the recognition of the contribution of epistemologies to localize the African descent in the center of their history and their present, promoting the decolonization of thought. The discussion about development in quilombola communities involves the actualization of rights of these communities and the recognition of knowledge and practices of communities for building sustainable and equitable environments.

Keywords: Quilombos; development; territory; sustainability.

\section{Introdução}

O quadro nacional de profundas e marcantes iniquidades sociais, fortemente associadas ao modelo convencional de desenvolvimento, torna urgente a reflexão e a busca por novos caminhos de organização econômica e social. O modelo "clássico" de desenvolvimento, centrado na busca incessante pelo crescimento econômico, não conseguiu promover a emancipação de muitos países e comunidades, ao passo que contribuiu para o agravamento da crise ambiental, tornando urgente a busca por outros modelos de desenvolvimento.

Os modelos de desenvolvimento centrados apenas no crescimento econômico e acumulação de capital, tidos como universais, partem de uma cosmovisão excludente, individualista e estruturada em políticas de dominação. A exclusão econômica e social, fruto desses modelos, é legitimada por princípios abstratos que, no plano do discurso, justificam ideologicamente o estado de coisas que preserva e aumenta a injustiça social em todo o planeta e no Brasil, particularmente.

Sob uma perspectiva historiográfica, a Era Moderna, fortemente associada ao modelo de desenvolvimento capitalista, industrial e científico, teve entre os principais fatos históricos a escravização de seres humanos do continente africano para as Américas e a colonização europeia na África, Ásia e América Latina. Significativamente, as categorias raciais surgiram durante esse período, convenientemente com o projeto de dominação que perpassava pela estratificação social como um dos pilares para a dominação e a exploração.

A resistência a esse sistema escravocrata no Brasil teve na formação dos quilombos uma de suas principais estratégias. Muito mais que espaço para abrigar escravizados fugidos, os quilombos se constituíram ao longo do tempo em territórios de 
sobrevivência física e cultural da presença e dos modos de vida africano no Brasil.

O termo quilombo passou a assumir um novo significado a partir da Constituição Federal de 1988 (art. 68) (Brasil, 1988), quando foi reconhecida a propriedade definitiva aos remanescentes das comunidades dos quilombos que estivessem ocupando suas terras, devendo o Estado emitir-lhes os títulos respectivos.

Apesar dos quase trinta anos de promulgação da Constituição Federal de 1988, a luta pela garantia dos títulos das terras usadas coletivamente ao longo da história, ainda representa um grande desafio para a efetivação da cidadania dos afrodescendentes quilombolas.

Diante do processo histórico de exclusão e negação de direitos, a reflexão acerca do desenvolvimento em comunidades quilombolas perpassa o reconhecimento da importância da terra, que possui uma simbologia e uma representação muito mais significativa para essa população. No Brasil, a categoria de povos e comunidades tradicionais (PCTs) refere-se a comunidades como grupos sociais culturalmente diferenciados, com formas próprias de organização econômica, política e de transmissão de conhecimentos (Brasil, 2007). Dentro desse enquadramento, as comunidades quilombolas são comunidades tradicionais marcadas pela conservação de princípios, saberes e práticas de matrizes afro-brasileiras.

O território, para essas comunidades, envolve não apenas espaço físico, mas múltiplas dimensões, que constroem identidades, resistências e vivências de utilização dos recursos naturais de forma equilibrada. A cosmologia holística e integradora na relação com a natureza, bem como a necessidade vital de manutenção dos recursos, é imperativa para a sobrevivência das comunidades. Assim, a discussão acerca das contradições e críticas na relação entre os modelos de desenvolvimento e seus impactos, positivos e negativos, sobre as comunidades tradicionais no Brasil, atravessam inegavelmente a dimensão sócio-espacial.

No contexto brasileiro, o agronegócio, os grandes empreendimentos hidrelétricos, os grandes projetos de exploração de minérios, a construção de complexos turísticos, entre outros fatores, vêm transformando diferentes territórios sob uma lógica de desenvolvimento associada aos interesses externos do mercado global. Dentro desse sistema, diversos conflitos surgem opondo grandes grupos empresariais (nacionais e internacionais) a outros grupos, tais como povos tradicionais quilombolas, que, ao vivenciarem esses conflitos ambientais nos territórios, sofrem com a queda da qualidade de vida e com o aumento dos riscos à saúde.

Essa realidade de negação de direitos, exploração de territórios tradicionais, relações de poder na disputa pelo uso dos territórios, negação do protagonismo quilombola na definição dos modelos, padrões e processos de desenvolvimento nas comunidades, nos impõe questões urgentes, tais como: Como discutir desenvolvimento sustentável com grupos que ainda lutam para ser reconhecidos enquanto cidadãos? Como superar a supremacia da concepção ocidental eurocêntrica e capitalista de desenvolvimento não aplicável para as comunidades tradicionais? Como pensar o "afrodesenvolvimento" como modelo capaz de promover a melhoria das condições de vida, conservação ambiental e cultural dos valores afro-brasileiros nas comunidades quilombolas? Quais caminhos epistemológicos são capazes de fomentar o desenvolvimento sustentável, 
enraizado nos valores civilizatórios afro-brasileiros, nas comunidades quilombolas?

É na reflexão dessas questões que o presente ensaio $^{1}$ se insere, com o objetivo de problematizar o discurso de desenvolvimento de comunidades quilombolas e a necessidade de reflexão acerca do desenvolvimento sustentável. Tal desenvolvimento é fundamentado nos princípios e valores civilizatórios afro-brasileiros como estratégia de melhoria das condições de vida e conservação ambiental e cultural em comunidades quilombolas.

\section{Desenvolvimento e a questão Quilombola no Brasil}

A ideia de progresso, melhoria, está comumente associada com a visão de uso, ocupação e transformação do planeta Terra. Essa ideia serviu de base para a construção da noção ocidental de desenvolvimento que se transformou em uma categoria científica e tópico central na agenda política e social (Rodriguez \& Silva, 2013).

O conceito inicial de desenvolvimento recupera o darwinismo social e se baseia na ideia de sucessão evolutiva de estágios, onde tal qual na natureza, as sociedades humanas evoluiriam de formas inferiores para formas superiores. Nessa hipótese, parte-se de um modelo de sociedade rudimentar culminando no modelo da civilização ocidental industrializada de consumo, considerada única e universal (Layrargues, 1997).

Apesar da noção de progresso embasar a ideia de desenvolvimento que surgiu a partir da Segunda
Guerra Mundial, quando a civilização superou uma grande crise e passou a perseguir o progresso com uma visão mais abrangente e democrática (Melo, 2003), essa noção trouxe consequências sociais e ambientais que estimularam a reflexão sobre a pertinência dessa ideia para a sobrevivência da humanidade.

O crescimento econômico sem precedentes vivenciado depois da Segunda Guerra Mundial pautado numa concepção materialista, antropocêntrica e exploradora dos recursos naturais, numa lógica de desenvolvimento industrial, impôs a necessidade de reflexão dos limites e das consequências desse modelo. Sachs (1993) aponta que seriam necessários cinco ou seis planetas como fonte de recursos e insumos e também como depósito para os desperdícios do progresso.

Dentre as teses que analisaram os efeitos do crescimento desordenado a partir da década de 1960, a publicação do Clube de Roma Limites do Crescimento, apresentou uma importante conclusão ao apontar que

É possível modificar essas tendências de crescimento e formar uma condição de estabilidade ecológica e econômica que se possa manter até um futuro remoto. O estado de equilíbrio global poderá ser planejado de tal modo que as necessidades materiais básicas de cada pessoa na Terra sejam satisfeitas, e que cada pessoa tenha igual oportunidade de realizar seu potencial humano individual (Meadows et al., 1972, p.24)

As críticas a essa concepção que pregava o equilíbrio global a partir da tese do crescimento zero e do ataque à filosofia do crescimento contínuo da

\footnotetext{
${ }^{1}$ Esse ensaio é fruto da pesquisa bibliográfica para o projeto "Saúde e Territorialidade: Saberes e práticas de Educação Popular em Saúde em territórios de comunidades quilombolas de Sergipe", que conta com apoio financeiro CHAMADA MS/CNPq/FAPITEC/SE/SES N 02/2013 - PPSUS SERGIPE.
} 
sociedade industrial, vieram, além dos teóricos do crescimento, de intelectuais de países do hemisfério sul, que alegaram que as sociedades ocidentais após um século de crescimento industrial acelerado, fecharam os caminhos para o desenvolvimento em países pobres, justificando essa conduta com uma retórica socioambiental (Bruseke, 2009).

Nesse cenário pessimista em relação ao futuro da humanidade diante da fraqueza do modelo convencional, adotado pelo ocidente na resolução dos problemas econômicos nos países periféricos, além da crise ambiental, a busca por novos estilos de desenvolvimento ganha força no final do século XX e início do século XXI.

A proposta do ecodesenvolvimento, apresentada em 1973 por Maurice Strong, como uma concepção alternativa de política de desenvolvimento, propõe, como princípios desse novo paradigma: a satisfação das necessidades básicas; a solidariedade com as gerações futuras; a participação da população envolvida; a preservação dos recursos naturais e do meio ambiente em geral; a elaboração de um sistema social garantindo emprego, segurança social e respeito a outras culturas; e o fomento de programas de educação (Sachs, 1993).

A crítica ao desenvolvimento industrial como método do desenvolvimento das regiões periféricas foi uma questão central na concepção dessa teoria, que, inicialmente, foi direcionada às regiões rurais da África, Ásia e América Latina. A aproximação dessa teoria com as comunidades tradicionais se dá na perspectiva de promoção de justiça social e reconhecimento das iniquidades produzidas pelo modelo hegemônico de desenvolvimento produtivista, estimulando novas ideias e modelos dentro de uma lógica de valorização do desenvolvimento endógeno e local.
As comunidades tradicionais geralmente possuem sistemas sociais e modos de vida baseados na horizontalidade temporal, com o intuito de garantir as necessidades das gerações futuras, sem comprometer as necessidades da geração presente e as contribuições das gerações passadas. Esse modo de conversão da relação temporal no processo de desenvolvimento representa um olhar ampliado para a implementação de estratégias que alinhem produção, conservação ambiental e equidade.

A ideia de comunidade está diretamente relacionada ao cuidado. Estar em comunidade, portanto, pressupõe estar entre pessoas com princípios, valores e outros atributos culturais semelhantes. "Numa comunidade, todos nos entendemos bem, podemos confiar no que ouvimos, estamos seguros a maior parte do tempo e raramente ficamos desconcertados ou somos surpreendidos. Nunca somos estranhos entre nós" (Bauman, 2003, p. 8).

A noção de comunidade apontada no parágrafo anterior nos possibilita entender a dimensão territorial nas comunidades tradicionais afro-brasileiras. Nos territórios quilombolas estão agregados os sentimentos de apropriação de uma porção do espaço, assim como quanto ao seu limite, a sua fronteira (Anjos, 2009). Dessa forma, pensar a territorialidade é muito importante neste processo, pois o limite do território não é necessariamente, físico, mas se estende até onde a comunidade reconhece sua influência, o seu exercício do poder. Nesse sentido, a territorialidade se apresenta no esforço coletivo em manter e ter definido o seu território e a terra na base de sua coletividade. Para Milton Santos, estas solidariedades definem usos e valores de múltiplas naturezas: culturais, antropológicas, econômicas, sociais, financeiras e ecológicas (Santos, 2005). 
Pensar comunidade afro-brasileira nos impele a recorrer ao princípio da integração, que nos mostra que na cosmovisão africana o homem está integrado ao universo, visto que todos os elementos do universo estão interligados numa interação dinâmica. A interdependência e a inter-relação entre tudo e todos são desejadas, pois a harmonia do todo depende da harmonia das partes. "Na cosmovisão africana, o indivíduo é singular, mas sua singularidade é construída de acordo com o comunitarismo, no âmbito do coletivo, socialmente" (Rocha, 2011, p. 34).

Ao romper com a lógica universalizadora e produtora de desequilíbrio ambiental e iniquidades sociais do modelo de desenvolvimento convencional, o ecodesenvolvimento operacionaliza o conceito a partir do amplo conhecimento das culturas e dos ecossistemas, sobretudo em como as pessoas se relacionam com o ambiente e como elas enfrentam seus dilemas cotidianos. Além disso, o fomento à participação social dos cidadãos no planejamento e tomada de decisões específicas para os problemas e necessidades particulares de cada região a curto, médio e longo prazo, busca equilibrar as dimensões econômica, social e ambiental.

O desenvolvimento sustentável, apontado erroneamente como sinônimo do ecodesenvolvimento (Layrargues, 1997), surge como proposta dominante nas discussões sobre meio ambiente e desenvolvimento a partir dos debates da Comissão Mundial Sobre Meio Ambiente em 1983. Como produto dessa comissão, o relatório Brundtland apresenta estratégias ambientais de longo prazo para se obter um desenvolvimento sustentável por volta do ano 2000 e daí em diante. As recomendações do relatório logo foram incorporadas como hegemônicas e como "verdade", reproduzidas em grandes confe- rências internacionais, programas governamentais sobre meio ambiente e desenvolvimento e até por setores não governamentais e empresariais na sua essência, ou adaptadas aos interesses e perfil de cada grupo (Lima, 2003).

Dentre as críticas ao discurso do desenvolvimento sustentável, destaca-se a ênfase dada às dimensões econômica e tecnológica e à concepção da capacidade do mercado em liderar o processo de transição para o desenvolvimento sustentável. Esse processo pode ser feito a partir da adoção de "tecnologias limpas", da contenção do crescimento populacional e do incentivo aos processos de produção e consumo ecologicamente orientados.

Ao analisarmos a ênfase dada à modernização ecológica e à fixação de níveis de consumo mínimos para países e comunidades não industrializadas, fica evidente o esvaziamento da dimensão política emancipatória do ecodesenvolvimento tão importante para países periféricos e comunidades tradicionais, como aponta Leff ao afirmar que

\begin{abstract}
antes que as estratégias de Ecodesenvolvimento conseguissem romper as barreiras da gestão setorializada de desenvolvimento [...] as próprias estratégias de resistência à mudança da ordem econômica foram dissolvendo o potencial crítico e transformador das práticas de Ecodesenvolvimento. Daí surge a busca de um conceito capaz de ecologizar a economia, eliminando a contradição entre crescimento econômico e preservação da natureza [...] Começa então naquele momento a cair em desuso o discurso do Ecodesenvolvimento, suplantado pelo discurso de Desenvolvimento Sustentável (Leff, 2001, p. 18).
\end{abstract}

Relacionar a questão quilombola aos modelos de desenvolvimento requer antes a compreensão da importância da questão racial. A importância da 
categoria raça ${ }^{2}$ na análise das relações sociais em lugares como o Brasil, que se constituiu como país a partir do sistema escravocrata, torna-se imprescindível na medida em que torna possível compreender a origem e os processos que constituem as persistentes e profundas iniquidades existentes no país. Compreendendo o racismo como um fator estruturante e determinante de distribuição seletiva das pessoas no território físico, que influencia também as possibilidades de acesso a direitos, inclusive às possibilidades de participar e usufruir dos benefícios do desenvolvimento, faz-se necessário refletir caminhos e estratégias de superação dessa lógica.

Além da noção de "raça", as concepções sobre quilombos variam desde o século XIX denotando os papéis nas relações de poder presentes na sociedade. As noções sobre quilombos se sobrepõem ao termo e denotam grupos de escravos fugidos; expressões de resistência cultural e política; grupos sociais étnica e culturalmente diferenciados; processos identitários coletivos e, mais recentemente, novos sujeitos de direitos socioculturais (Rodrigues, 2010).

A Associação Brasileira de Antropólogos (ABA) traz uma definição mais contemporânea e "operacional" ao conceituar quilombo como "toda comunidade negra rural que agrupa descendentes de escravizados vivendo da cultura de subsistência, onde as manifestações culturais têm forte vínculo com o passado" (ABA, 1994).

Na atualidade, os quilombos contemporâneos são definidos como

Comunidades negras rurais habitadas por descendentes de africanos escravizados, que mantêm laços de parentesco e vivem, em sua maioria, de culturas de subsistência, em terra ocupada secularmente pelo grupo [...] (Moura, 2007, p. 2).

O desafio para as comunidades quilombolas efetivarem o direito à posse da terra e dos recursos do território, é fator determinante no processo de produção de exclusão social, conforme destaca Carril (2006)

As formas de uso da terra e dos recursos do território têm mostrado que o acesso a terra apresenta demandas históricas construídas nas quais as questões do trabalho e as estratégias de sobrevivências vêm se colocando como aspectos de crucial importância para a definição de um traço de lutas existentes no Brasil. (Carril, 2006, p.158).

Essa realidade nos impõe a necessidade de refletir o quanto o discurso e as práticas de desenvolvimento sustentável em comunidades tradicionais precisam se alinhar às necessidades reais das comunidades quilombolas. $\mathrm{O}$ reconhecimento da cidadania e a garantia dos direitos básicos de sobrevivência física e cultural pelas quais as comunidades quilombolas lutam há séculos devem ser questões prioritárias. Se o Estado não consegue "retirar do passado" a exploração e a exclusão garantindo a sobrevivência no presente, como pensar/realizar um projeto de futuro para essas comunidades?

De modo geral, as comunidades tradicionais têm seus modos de vida influenciados por uma cosmovisão holística com olhar biocêntrico, onde comunidade e natureza fazem parte de um todo em harmonia. Nessa concepção, as relações da comunidade com o meio ambiente estão imbricadas com o território, que vai do simbólico ao concreto e atra-

${ }^{2}$ A categoria raça é compreendida aqui, não como categoria biológica, mas enquanto constructo social determinante de desigualdades sociais. 
vessa todas as ações sociais nessas comunidades, sejam elas relacionadas à saúde, rituais, cultura, religião, resistência, enfim, à própria sobrevivência física e cultural desses grupos populacionais.

A despeito da tentativa de viver numa lógica e a partir de princípios diferentes da lógica ocidental, o desafio de sobreviver e "desenvolver" as comunidades é cotidiano. Como manter e fortalecer princípios de fraternidade, equidade, justiça social e ambiental, em um país que vive à luz de um modelo de desenvolvimento que exige, para seu estabelecimento e manutenção, a cristalização da exploração e da opressão, invisibilizando, assim, a luta e os direitos da maioria, para viabilizar os privilégios e lucro de uma minoria?

O processo de produção de vulnerabilidades no Brasil pode ser compreendido como resultado do modelo de desenvolvimento que tem por base a maximização da exploração de recursos naturais em detrimento de modelos de desenvolvimento endógenos que produzam solidariedade e cidadania comunitária na busca por melhoria do bem-estar da população de uma localidade (Henriques \& Porto, 2012).

Nesse cenário de iniquidades decorrentes do modelo de desenvolvimento insustentável hegemônico no Brasil, faz-se necessário refletir o impacto do racismo ambiental sobre as comunidades quilombolas. O racismo ambiental é definido como

o conjunto de ideias e práticas das sociedades e seus governos, que aceitam a degradação ambiental e humana, com a justificativa da busca do desenvolvimento e com a naturalização implícita da inferioridade de determinados segmentos da população afetados - negros, índios, migrantes, extrativistas, pescadores, trabalhadores pobres, que sofrem os impactos negativos do crescimento econômico e a quem é imputado o sacrifício em prol de um benefício para os demais. (Herculano, 2006, p.11)

O mapa de Conflitos Envolvendo a Justiça Ambiental e Saúde no Brasil ${ }^{3}$ mostra o quanto o racismo ambiental é um entrave à efetivação de um modelo de desenvolvimento sustentável no Brasil. O mapa demonstra trezentos e quarenta e três (343) conflitos ambientais no ano de 2015. Destes, 33,57\% e 21,55\%, respectivamente, envolveram povos indígenas e quilombolas, que estavam entre as principais populações atingidas. Dentre as consequências dos conflitos, a alteração no regime tradicional de uso e ocupação do território é o principal impacto apontado, presente em $65,66 \%$ dos conflitos. Outro impacto relevante, presente em $40,07 \%$ dos conflitos, é a falta/irregularidade na demarcação de território tradicional. Pode-se perceber que os principais impactos atingem diretamente as territorialidades das comunidades tradicionais, o que afeta, entre outras dimensões da vida, o processo de adoecimento e morte dentro das comunidades tradicionais (Lacerda \& Silva, 2016).

O reconhecimento do racismo ambiental põe em evidência a necessidade de compreensão e de análise do peso dos fatores raciais nas situações de injustiça decorrentes do modelo de desenvolvimento hegemônico. Essa constatação é urgente e imprescindível nesse debate, visto que os efeitos e consequências negativas associadas ao modelo de desenvolvimento baseado na exploração da natureza

\footnotetext{
${ }^{3}$ Mapa de Conflitos Envolvendo a Justiça Ambiental e Saúde no Brasil, que foi desenvolvido pela FIOCRUZ, com o apoio do Departamento de Saúde Ambiental e Saúde do Trabalhador do Ministério da Saúde. Disponível em http://www.conflitoambiental.icict.fiocruz.br/
} 
impactam de forma desigual os diferentes grupos populacionais.

Evidenciar e discutir as desigualdades e as discriminações étnicas e raciais é um passo determinante para superá-las. Reconhecer essas diferenças se faz necessário pela existência das vítimas do racismo ambiental bem como por seus impactos no agravamento das desigualdades sociais no Brasil.

$\mathrm{Na}$ arena de disputa de projetos de desenvolvimento, as comunidades tradicionais apresentam demandas urgentes a serem encaminhadas com o intuito de possibilitar as condições necessárias para o seu fortalecimento socioambiental delas. Questões relativas à saúde, educação, trabalho, bem como aos mecanismos de compensação e promoção de cidadania, como as ações afirmativas/cotas e a titulação territorial, são questões que devem ser estruturantes dos projetos de desenvolvimento no sentido de reduzir o fosso da desigualdade no Brasil.

Nesse sentido, a valorização da autonomia política e da singularidade cultural de cada comunidade são passos necessários para a realização de uma sustentabilidade complexa (Diegues, 2001), capaz de superar o economicismo, o universalismo e a supervalorização mercadológica, implícitos no discurso oficial de desenvolvimento sustentável (Lima, 2003).

A sustentabilidade das comunidades quilombolas não pode ser alcançada sem o reconhecimento e combate às iniquidades sociais e políticas, bem como a valorização dos valores civilizatórios afro-brasileiros de respeito à vida.

\section{Valorização do pensamento afro- brasileiro na construção de conceitos de desenvolvimento aplicáveis às comunidades quilombolas}

A promoção do protagonismo afro-brasileiro no desenvolvimento de um pensamento crítico capaz de questionar e transformar os modelos de produção de desigualdades e injustiças no Brasil perpassa pela reflexão dos elementos epistemológicos que auxiliaram no processo de consolidação do hegemônico pensamento eurocêntrico ocidental.

Além da configuração das "peças do tabuleiro" da geopolítica mundial, o processo de colonização, estrategicamente, se deu também no campo do saber, atribuindo valor e legitimidade à produção ocidental eurocêntrica em detrimento das demais culturas.

Compreender as relações de poder que permeiam os discursos e projetos de desenvolvimento, requer reconhecer o papel do saber na legitimação da dominação, já que, segundo Foucault "Não há relação de poder sem constituição correlativa de um campo de saber, nem saber que não suponha e não constitua ao mesmo tempo relações de poder" (Foucault, 1999, p.32).

Essa relação saber/poder na intersecção com a questão racial encontra eco nas manifestações de racismo epistêmico, que é apontado por Grosfroguel (2007) como um dos racismos mais invisibilizados no "sistema-mundo capitalista/patriarcal/moderno/ colonial" e que:

opera privilegiando as políticas identitárias (identity politics) dos brancos ocidentais, ou seja, a tradição de pensamento e pensadores dos homens ocidentais (que quase nunca inclui as mulheres) é considerada como 
a única legítima para a produção de conhecimentos e como a única com capacidade de acesso à "universidade" e à "verdade". O racismo epistêmico considera os conhecimentos não-ocidentais como inferiores aos conhecimentos ocidentais. (Grosfroguel, 2007, p. 32)

As ideias racialistas estiveram presentes na estruturação do pensamento das ciências econômicas da tradição neoclássica, que serviram de bases para a construção da noção de desenvolvimento convencional, estigmatizando grupos e determinando os papéis no cenário de construção de concepções e projetos de desenvolvimento.

\section{Conforme Jevons}

É evidente que os problemas deste tipo dependem muito da índole da raça. Pessoas de temperamento enérgico acham o trabalho menos penoso que seus camaradas e, se elas são dotadas de sensibilidade variada e profunda, nunca cessa seu desejo de novas aquisições. Um homem de raça inferior, um negro, por exemplo, aprecia menos as posses, e detesta mais o trabalho; seus esforços, portanto, param logo. Um pobre selvagem se contentaria em colher frutos quase gratuitos da Natureza, se fossem suficientes para dar-lhe sustento; é apenas a necessidade física que leva ao esforço. O homem rico na sociedade moderna está aparentemente suprido com tudo que ele pode desejar e, no entanto, frequentemente trabalha por mais sem cessar (1983[1871], p. 116).

Frente ao racismo epistêmico, a busca pela reflexão a partir de outras epistemologias, como a afro-brasileira, não deve ser compreendida como um "revanchismo epistêmico" ou tentativa de inverter as posições na arena na geopolítica do saber. Deve ser papel do pesquisador buscar e apresentar alternativas epistemológicas considerando a complexidade dos fenômenos e a diversidade de formas de pensar e construir conhecimento. Apesar da epistemologia ser universal, dada a capacidade humana de conhecer, as formas de aquisição de conhecimento variam segundo os contextos socioculturais em que as reivindicações de conhecimento são formuladas e articuladas (Kaphagawini \& Malherbe, 2002).

Questionar a hegemonia e apresentar alternativas à epistemologia eurocêntrica, se faz um imperativo para a descolonização do conceito de desenvolvimento, na medida em que esse sempre privilegiou um padrão de pensamento no ocidente que estuda o "outro" como objeto e não como sujeito produtor de conhecimentos.

Fomentar a utilização de outras epistemologias rompe com a tradição clássica da pesquisa ocidental, já que,

\begin{abstract}
em vez de um sujeito branco estudando sujeitos não-brancos como objetos do conhecimento, assumindo-se a si mesmo como um observador neutro não situado em nenhum espaço nem corpo ("ego-política do conhecimento"), o que lhe permite portanto reclamar uma falsa objetividade e neutralidade epistêmica, temos a nova situação de sujeitos das minorias discriminadas estudando a si mesmos como sujeitos que pensam e produzem conhecimentos a partir de corpos e espaços subalternizados e inferiorizados ("geopolítica e corpo-política do conhecimento") pela epistemologia racista e o poder ocidental. (Grosfroguel, 2006, p. 32).
\end{abstract}

Essa posição epistemológica descolonizadora e política reflete o combate ao racismo epistêmico, ao questionar a visão hegemônica branca acerca das minorias discriminadas que direcionava seus esforços, inclusive intelectuais, em tornar estes últimos responsáveis pela sua própria condição de marginalização, pobreza e vulnerabilidade.

Nesse contexto, Grosfroguel destaca que 
Isso não apenas provocou o racismo epistêmico que atribui e reconhece a produção de teoria aos sujeitos ocidentais brancos enquanto os não-brancos produzem folclore, mitologia ou cultura mas não conhecimento de igual para igual com o ocidente, mas abriu um potencial para a descolonização do conhecimento ao desafiar a "ego-política do conhecimento" cartesiana das ciências ocidentais, opondo-lhe a "geopolítica e a corpo-política do conhecimento" dos sujeitos subalternos (Grosfroguel, 2006, p. 32).

A proposta de um olhar descolonizador e afrocentrado sobre a epistemologia opõe-se aos mitos da objetividade e neutralidade, que contribuíram para invisibilizar e deslegitimar quem fala e a partir de qual corpo e espaço epistêmico nas relações de poder se fala.

Compreender a vivência cotidiana das comunidades quilombolas impõe ao pesquisador, imbuído de intencionalidade emancipatória na sua prática de reflexão e produção do conhecimento, o imperativo ético e político de revisitar o arcabouço teórico-metodológico produzido pelos povos de origem afro-brasileira. Essa rica e pouco conhecida produção tem sido historicamente invisibilizada pelo racismo epistêmico, que universaliza e legitima as concepções eurocêntricas de análise dos modos de vida de comunidades tradicionais.

Nesse sentido, está a importância da compreensão dos valores africanos de referência e identidade, que se configuram como importantes pressupostos na afirmação da cultura afro-brasileira. Assim, para articulá-los e recuperá-los, utilizando-os na construção do habitus $^{4}$ afro-brasileiro, faz-se necessária uma orientação afrocentrada na pesquisa e no pensamento (Asante, 1980).

A filosofia africana apresenta um caráter espacial ao conceber que "um pensamento não pode existir sem saber de que lugar se origina, qual caminho de origem e qual destino seguir. É necessário saber de onde pisa para dialogar com outras construções de caminhos" (Santos, 2010, p. 7).

Uma categoria ontológica e epistemológica no pensamento africano é $u b u n t u^{5}$. Um conceito que nos aproxima da compreensão das relações entre as pessoas e com a natureza presente nas comunidades afro-brasileiras. Uma delas é a ideia de comunidade, segundo a qual as pessoas dependem de outras pessoas para serem pessoas, pois a noção central do ubuntu é "Eu sou, porque nós somos".

É nitidamente perceptível a diferença entre esse conceito e a noção europeia sobre a natureza humana, que tem a liberdade como valor fundamental e, concebe, assim, com primazia a existência do poder de escolha dos indivíduos sobre suas ações. Já para o ethos do ubuntu, em oposição à valorização ocidental do indivíduo, não é o valor individual que ganha ênfase, uma pessoa não só é uma pessoa por meio de outras pessoas, mas também por meio de todos os seres do universo. Cuidar "do outro",

\footnotetext{
${ }^{4}$ Categoria proposta por Bourdieu (2003) que explica que as percepções e os sentidos atribuídos às manifestações fenomênicas da saúde dependem da posição que os sujeitos ocupam nos diversos campos do espaço social e de suas relações, muitas vezes de lutas e conflitos, mas também cooperativas e comunicativas (Vieira, 1999). O habitus sintetiza a incorporação de elementos relativos à história coletiva e à trajetória individual no inconsciente dos indivíduos, atuando como matriz de percepção e classificação das práticas, como um operador prático que ajusta condições objetivas e esperanças subjetivas (Breilh, 2006).

${ }^{5}$ Ubu-ntu é uma categoria ontológica e epistemológica no pensamento africano do povo de língua banta. É a indivisível unicidade e inteireza da epistemologia e ontologia. Ubu é geralmente entendido como a existência e pode ser dito como uma ontologia distinta. Enquanto ntu é um ponto no qual a existência assume uma forma concreta ou um modo de ser no processo contínuo de desdobramento que pode ser epistemologicamente distinto (Ramose, 2002).
} 
portanto, também implica o cuidado para com o meio ambiente e os seres não humanos.

Finch III \& Nascimento (2009) ressaltam que o pensamento afrocêntrico tem seus primeiros registros a partir do século XVIII, incluindo depoimentos de africanos submetidos ao holocausto da escravatura mercantil europeia. Eles destacam relatos e fatos relevantes tais como: a solicitação à justiça de retorno à África feita por escravizados alforriados em 1773 em colônias inglesas nos Estados Unidos e a publicação de obras abolicionistas por africanos antiescravistas com propostas de melhor tratamento, libertação e indenização do africano pelos danos sofridos.

No Brasil, destaca-se a "Carta da escrava Esperança Garcia do Piauí”. Trata-se de um texto dirigido ao Governador da Capitania do Piauí apresentando queixas contra o administrador das fazendas reais. A carta tem importância para a derrubada do mito da passividade, da convivência pacífica e da democracia racial dos escravizados com os senhores no Brasil, no cativeiro africano ali existente (Ferreira, 2008).

Durante o século XX, diversos ativistas e acadêmicos africanos e afrodescendentes empenharam esforços para a consolidação do paradigma afrocentrado para as questões relativas à África e à diáspora.

Os principais estudos iniciaram na década de 1960 em Núcleos de Estudos Negros em algumas universidades nos Estados Unidos, como tentativa de formular teorias, abordagens e epistemologias originais numa perspectiva negra, opondo-se à naturalização e à hegemonia das epistemologias eurocêntricas acerca de questões africanas. No final da década de 1970, Molefi Asante começou a falar sobre a necessidade de uma orientação afrocêntrica da informação.
A afrocentricidade é definida por Asante como "um tipo de pensamento, prática e perspectiva que percebe os africanos e afrodescendentes como sujeitos e agentes de fenômenos atuando sobre sua própria imagem cultural e de acordo com seus próprios interesses humanos" (Asante, 2009, p. 93).

Esse paradigma ampara-se na afirmativa que os africanos e afrodescendentes devem "operar como agentes autoconscientes" de sua história, cuja auto definição positiva e assertiva deve partir das "culturas africanas". Essa perspectiva rompe com a ideia de "neutralidade" de ideias, conceitos e teorias, ao considerá-las enquanto produto de uma matriz cultural e de uma história particular (Mazama, 2009, p. 111).

A afrocentricidade é uma teoria que ressalta a necessidade de demarcar a localização do sujeito para desenvolver um engajamento teórico próprio ao grupo social e fundamentado em sua experiência histórica e cultural. Surge em oposição à supremacia branca, que se expressou ao longo da história tanto como processo físico, marcado pela violência e brutalidade nos processos de escravização e colonização europeia, como na ocupação do psicológico e intelectual africano e afrodescendente por meio da massificação de ideias, teorias e conceitos europeus, tomados como naturais, universais e normais (Mazama, 2009).

De forma assertiva e direta, Asante destaca que

Ao recuperar nossas próprias plataformas, ocupar nossos próprios espaços culturais e acreditar que nossa forma de contemplar o universo é tão válida quanto qualquer outra, poderemos atingir a qualidade de transformação de que precisamos para participar plenamente numa sociedade multicultural. Entretanto, sem esse equilíbrio centrado não trazemos quase nada 
à mesa multicultural, a não ser uma versão mais escura da brancura. (Asante, 1998, p. 8)

Um conceito central da afrocentricidade, e bastante útil para a discussão acerca de desenvolvimento em comunidades quilombolas, é o conceito de agência. Definido como a capacidade de dispor de recursos psicológicos e culturais necessários para o avanço da liberdade humana, esse conceito denota "a capacidade de pensar, criar, agir, participar e transformar a sociedade por força própria" (Nascimento, 2009, p. 192). Enfim, um agente é "um ser humano capaz de agir de forma independente de seus interesses". (Id Ibid). Na linha oposta, a "desagência" é entendida como qualquer situação na qual o africano seja descartado como ator ou protagonista em seu próprio mundo.

O olhar afrocentrado no estudo das relações entre desenvolvimento e ambiente em comunidades quilombolas no Brasil perpassa pela necessidade de alinhar epistemologia e análise dos fenômenos numa perspectiva emancipatória. $\mathrm{O}$ fomento ao protagonismo/agência dos afrodescendentes na descrição das suas experiências deve ter como referência de análise os valores civilizatórios afro-brasileiros.

Diante desse processo civilizatório, é importante destacar a impossibilidade de se pensar a afrocentricidade dissociada da alteridade, já que o descendente africano no Brasil tem sua identidade formada, também, sob a influência de valores branco-europeus e indígenas. Entretanto, a pertinência da abordagem se ampara na necessidade de problematizar o padrão ocidental como característica principal da "civilização brasileira".

As concepções e práticas de desenvolvimento em comunidades quilombolas devem ser diretamente influenciadas por características culturais afro-brasileiras tais como: centralidade na comunidade, matriarcalidade, respeito à tradição, harmonia com a natureza.

Tomar a perspectiva afrocentrada como referência epistemológica e política capaz de questionar a ordem estabelecida, bem como propor caminhos estruturados na experiência dos afro-brasileiros, torna-se um desafio. É imperativo ressignificar o olhar acadêmico sobre a experiência histórica de produção de modos de vida capazes de garantir a resistência e a sobrevivência da cultura afro-brasileira, bem como a conservação dos recursos naturais nas comunidades.

O reconhecimento da produção de conhecimento afrocentrado contribui para a construção de concepções e práticas de desenvolvimento, entendidos aqui como um processo de fortalecimento da agência - "a capacidade de pensar, criar, agir, participar e transformar a sociedade por força própria" (Nascimento, 2009, p. 98) - dos afro-brasileiros na construção de processos de melhoria das condições de vida, redução das desigualdades e conservação dos territórios, valores e princípios afro-brasileiros.

\section{Complexidade e diálogo de saberes acerca do desenvolvimento em comunidades quilombolas}

A complexidade das questões imbricadas no debate sobre desenvolvimento sustentável em populações tradicionais só pode ser compreendida a partir de um pensamento também complexo, capaz de estimular no pesquisador um modo de pensamento aberto e flexível, dentro de uma perspectiva epistemológica integradora e abrangente capaz de romper com propostas lineares e superficiais de 
produção do conhecimento, que concebem o universo como uma "máquina determinística perfeita" (Morin, 2009).

A análise das relações do homem com o meio, natural e social, requer a superação da concepção reducionista e simplificadora tradicional na ciência, que comumente dilui a complexidade dos fenômenos e das práticas humanas a fim de revelar a ordem simples a que eles obedecem.

O "Paradigma Dominante" é construído pela racionalidade da ciência moderna e estabelece um "modelo totalitário" de observar e compreender o mundo ao negar a racionalidade de todas as formas de conhecimento não pautadas pelos seus princípios epistemológicos e suas regras metodológicas (Santos, 2003).

Esse paradigma pressupõe a separação entre ser humano e natureza; visa a conhecer a natureza para dominá-la e controlá-la; assenta-se na redução da complexidade; possui como pressupostos a ordem e a estabilidade do mundo (Morin, 2002; 2003).

Por outro lado, o paradigma afrocentrado tem um conjunto de valores, crenças e ideias que constrói um modo específico de observar, agir e compreender a relação entre as pessoas e com a natureza em suas dimensões visível e invisível, e que estabelece uma ética e uma estética para o viver coletivo, fazendo com que seus limites não coincidam com a dimensão geográfica do continente africano (Alves et al., 2015).

O totalitarismo tendencial da ciência moderna produziu ideias e concepções discriminatórias acerca de outras formas de se relacionar e compreender os fenômenos. Carvalho (2013) aponta algumas consequências desse processo, as quais, nitidamente, impactaram os povos afro-brasileiros afirmando que
$\mathrm{O}$ arrogante pensamento domesticado, moderno, científico, que se consolidou a partir do século XV, cercado de certezas, leis, determinismos, causalidade, teleologias, deixou de lado a preocupação com a totalidade, com a intuição, com o imaginário, passando a se concentrar no entendimento do fragmento, da parte, supondo que através deles seria possível atingir uma objetividade sem parênteses. Com isso, virou as costas para o sujeito, para a incerteza e para a complementaridade, privatizou terras e mares, considerou magias e mitos como algo irracional, produto descartável criado pela mente obscura de selvagens, ou por alucinações dos civilizados (Carvalho, 2013, p. 40).

Ao refletir sobre os limites da racionalidade capitalista e sua inerente produção de escassez, para muitos, e desigualdades, Milton Santos traz à tona formas de resistência que os grupos excluídos desenvolvem, chamando atenção para o fato que

$\mathrm{Na}$ esfera da racionalidade hegemônica, pequena margem é deixada para a variedade, a criatividade, a espontaneidade. Enquanto isso, nas outras esferas surgem contraracionalidades e racionalidades paralelas, corriqueiramente chamadas de irracionalidades, mas que na realidade constituem outras formas de racionalidade, produzidas e mantidas pelos que estão "em baixo", sobretudo os pobres, que desse modo conseguem escapar ao totalitarismo da racionalidade dominante (Santos, 2000, p. 58)

A desestruturação dos ecossistemas, guiado pela razão tecnológica e pela lógica do mercado, acabaram por criar a necessidade de abordagens integradoras de conhecimento capaz de compreender causas e a dinâmica dos processos socioambientais, os quais, devido a sua complexidade, extrapolam a capacidade de conhecimento dos paradigmas científicos dominantes, exigindo uma recomposi- 
ção holística, sistêmica e interdisciplinar do saber (Leff, 2001).

Como possibilidade de superação da crise socioambiental gerada pela lógica capitalista de exploração guiada pela racionalidade científica, o saber ambiental apresenta uma possibilidade de hibridização das ciências com o campo dos saberes "tradicionais", populares e locais. Nesse sentido, a produção "interdisciplinar" de conhecimentos assume o compromisso de fomentar a autonomia cultural, por meio do protagonismo e autogestão dos recursos das comunidades, pela propriedade das terras de uma população, por meio da utilização de conhecimentos que promovam a apropriação coletiva dos recursos naturais, uma produção sustentável e a equânime divisão da riqueza. Dessa forma, as necessidades básicas das comunidades e a melhoria das condições de vida seriam os pilares dos projetos de desenvolvimento (Leff, 2000).

A proposta de hibridização das ciências com os saberes e fazeres tradicionais se alinha à proposta da transdisciplinaridade de unir a tradição à ciência, procurando pontos de vista a partir dos quais seja possível torná-las interativas, fazendo-as sair de sua unidade, respeitando as diferenças, apoiando-se especialmente numa nova concepção da natureza.

Para que as comunidades tradicionais possam se manter sob a perspectiva da sustentabilidade, precisam adequar suas características às inter-relações com o lugar e, principalmente, agregar às suas necessidades pessoais e coletivas as atitudes de valoração, respeito e cuidado com o ambiente que as abriga.

Nesse processo se faz necessário inventariar os elementos ambientais, culturais e históricos que servirão de constructo para a identidade dessa comunidade, conferindo-lhes legitimidade. Diegues (2003) postula que a construção dessas comunidades está intimamente relacionada à construção de sociedades sustentáveis, o que, para o referido autor, pressupõe pensar localmente, porém com resultados que alcancem o nível macro das relações sociais.

O reconhecimento dos elementos culturais e históricos é fundamental na construção de comunidades sustentáveis. A valorização dos modos de vida solidários de respeito à natureza, não com o intuito de capitalizar sobre os recursos naturais, mas como necessidade de manutenção da vida, em todas as suas formas, constitui um fundamento de sociedades sustentáveis (Diegues, 2003).

A valorização do conhecimento tradicional aponta diretrizes para modelos alternativos de desenvolvimento. O conjunto de saberes tradicionais engloba aspectos do mundo natural ao sobrenatural, é transmitido oralmente de geração em geração e estrutura a organização econômica e social com reduzida acumulação de capital, não utilização de mão de obra assalariada, valendo-se, em seu lugar, da apropriação e do uso coletivo dos recursos naturais presentes nos territórios.

A produção nas comunidades tradicionais está predominantemente organizada em atividades de pequena escala como agricultura, pesca, extrativismo e artesanato. Um ponto importante nesse modo de produção é a contribuição delas para a conservação ambiental, visto que os produtores possuem conhecimento dos recursos naturais, seus ciclos biológicos e outras informações importantes que são passadas de geração em geração, além da utilização de recursos naturais renováveis. 
A Convenção sobre Diversidade Biológica ${ }^{6}$ reconhece a estreita e tradicional dependência de recursos biológicos de muitas comunidades locais com estilos de vida tradicionais e aponta para a necessidade de repartir equitativamente os benefícios da utilização do conhecimento tradicional, de inovações e de práticas relevantes à conservação da diversidade biológica e à utilização sustentável de seus componentes. Além disso, essa convenção aponta para a necessidade de:

respeitar, preservar e manter o conhecimento, inovações e práticas dessas comunidades relevantes à conservação e à utilização sustentável da diversidade biológica e incentivar sua mais ampla aplicação com a aprovação e a participação dos detentores desse conhecimento, inovações e práticas. (Brasil, 2002, p. 11)

A união de saberes dá sentido e legitima o senso comum e os saberes locais, levando o conhecimento científico a transformar-se nele e, conferir-lhes racionalidade ambiental. E, apesar dos desafios epistemológicos trazidos por uma nova racionalidade ambiental, é fundamental reconhecer a gama de conhecimentos gerados e as práticas ambientalmente positivas que esta nova realidade apresenta. Neste contexto, Leff (2001) destaca que a racionalidade ambiental incorpora o equilíbrio ecológico como condição inicial do desenvolvimento sustentável. Por outro lado, se funda em princípios éticos (respeito e harmonia com a natureza) e valores políticos (democracia participativa e equilíbrio social) como novos fins do desenvolvimento.

Aplicar os saberes ambientais é o modo de interligar o homem à natureza. Afinados a uma perspectiva da complexidade, possuem organização fisiológica perfeita, ou seja, têm suas necessidades saciadas, pois a natureza, no sentido físico do termo, tudo dá. Neste sentido, somente a partir da conservação dos traços originais será possível a convivência harmoniosa do ser consigo mesmo.

Faz-se imprescindível a discussão da importância de um pensamento territorializado, fornecendo uma rica reflexão para a crítica da universalização do conceito de cultura que não faz ligação com os fatos sociais ou históricos do próprio lugar (Santos, 2010). Dessa forma, pode-se compreender o modo de vida que caracteriza um grupo por meio do estudo de sua cultura, que envolve a análise de comportamentos, costumes e crenças aprendidos e compartilhados.

Diante do exposto, compreendemos o imperativo de pensar as relações entre desenvolvimento, território e ambiente em comunidades quilombolas numa perspectiva centrada na experiência cultural dessas comunidades. Faz-se necessário tomar como pressuposto inicial a percepção da complexidade existente nessas relações, bem como a importância de evidenciar seus múltiplos aspectos, a fim de superar a superficialidade presente na análise sob o ponto de vista universalista, excludente e, até racista, presente nos discursos e projetos de desenvolvimento predominantes no Brasil.

Enfim, a superação dos problemas atuais decorrentes dos modos vigentes de produção e desenvolvimento, perpassa pelo reconhecimento de formas tradicionais de interação entre o homem e o meio ambiente. Nesse caminho, romper com hierarquias e preconceitos em relação aos conhe-

${ }^{6}$ Tratado internacional multilateral assinado durante Conferência das Nações Unidas sobre Meio Ambiente e Desenvolvimento realizada no Rio de Janeiro em 1992. 
cimentos de comunidades tradicionais torna-se imprescindível para a produção de saberes capazes de apresentar um novo panorama fincado na esperança e no respeito entre as pessoas juntamente com o meio ambiente.

\section{Princípios e valores para modelos de desenvolvimento em comunidades quilombolas}

A cultura afro-brasileira tem, entre suas características centrais, valores e princípios que demarcam elementos indispensáveis para a construção de modelos de desenvolvimento adequados às especificidades e necessidades das comunidades quilombolas. Dentre essas características, podemos destacar a centralidade na comunidade; o respeito à tradição; o alto nível de espiritualidade e o envolvimento ético; a harmonia com a natureza; a natureza social da identidade individual; a veneração dos ancestrais e a unidade do ser (Karenga, 2003).

Pode-se perceber que essas características demonstram modos de ser e de atuar no mundo. Determinam os modos de interagir com ele e de visualizá-lo, atuando também sobre as relações sociais, as relações com o meio ambiente e as relações com o metafísico, ou seja, com a própria existência. Dessa forma, faz-se imprescindível vincular conceitos, estratégias e ações acerca do desenvolvimento em comunidades quilombolas ao seu rico, complexo e aplicável arcabouço de saberes e práticas de harmonização das relações comunitárias e ambientais.

O ponto de partida para a compreensão ontológica da relação entre o homem e a natureza, na perspectiva africana, é o entendimento sobre o axé. $\mathrm{O}$ axé, sob esse olhar, é uma força que resume as energias cósmicas e reside em todos os aspectos da natureza e do universo, configurando-se como atributo vital dos seres, abrangendo os reinos mineral, vegetal e animal, fazendo a natureza povoar-se de forças ligadas aos seus mais variados domínios (Leite, 1996).

Outro aspecto importante é o protagonismo feminino nas dinâmicas relacionais comunitárias e ambientais na cosmologia africana. A mulher é detentora de uma forte personalidade comunitária, religiosamente falando. É ela a detentora, também, da força espiritual, portadora de muito axé, o que viabiliza sua expansão e preservação por meio dos rituais (Lopes, 2008).

Em oposição à racionalidade tecno-científica, que atribui superioridade à civilização ocidental, um dos princípios fundamentais dentro da perspectiva afrocentrada é a ancestralidade. Esse princípio funda-se no respeito às experiências dos mais velhos, na comunicação que pode existir entre o mundo dos vivos e o mundo dos mortos, espíritos e entidades sobrenaturais. Os ancestrais fazem a ligação entre o mundo visível e o invisível, colaborando com a comunidade, orientando suas ações. A preservação da memória dos antepassados não leva somente a olhar o passado, mas também a estabelecer diálogos com ele, absorvendo a sabedoria dos ancestrais, que abrirão caminhos para novos tempos (Rocha, 2011). Essa relação temporal integradora possibilita encontrar caminhos já percorridos como possibilidade de solidificar as vivências presentes e preparar os passos futuros na construção de ambientes e comunidades sustentáveis.

Nesse sentido, a oralidade enquanto forma de preservação de sabedoria e do conhecimento dos antigos e ancestrais é um princípio fundamental na condução de projetos e estratégias de desenvolvi- 
mento em comunidades quilombolas. O patrimônio cultural, ecológico e sanitário que fez com que essas comunidades resistissem às diversas formas de violência e tentativas de "genocídio cultural", fortalecendo os laços comunitários e a vida harmônica com o meio ambiente, resultam em muito à força da oralidade.
Além dos princípios e valores afro-brasileiros, o desenvolvimento sustentável em comunidades quilombolas deve levar em consideração aspectos políticos, sociais, éticos, epistemológicos e tecnológicos que promovam o protagonismo comunitário, a redução da vulnerabilidade social e a emancipação das comunidades (Tabela 1).

TABELA 1 - Princípios para o desenvolvimento sustentável em comunidades quilombolas.

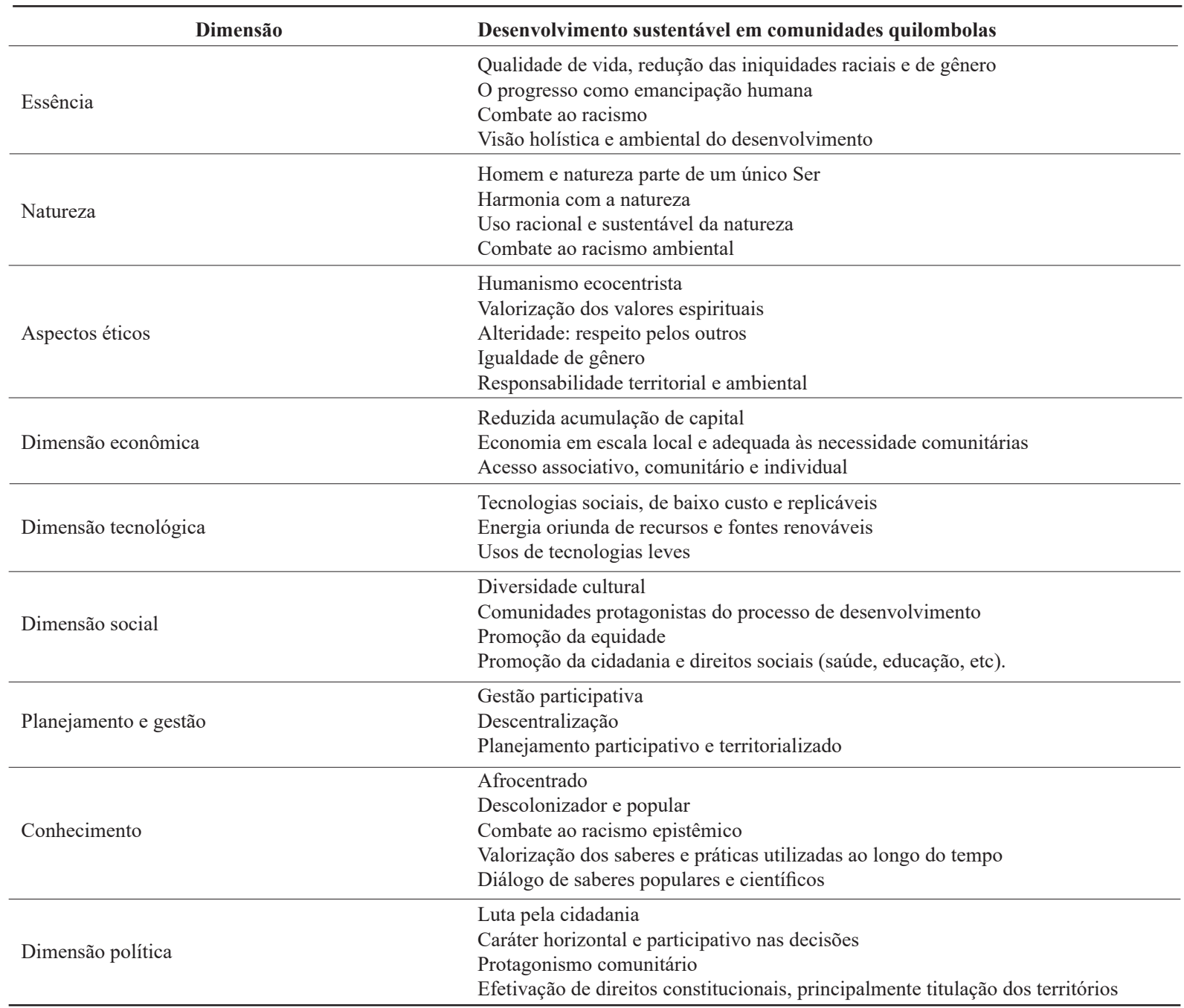


As proposta de agências governamentais, universidades, organizações não-governamentais, entre outras instituições que debatem e fomentam o desenvolvimento em comunidades quilombolas no Brasil, devem partir das necessidades e particularidades das comunidades. Para tanto, faz-se necessário superar os preconceitos e estereótipos racistas que não reconhecem os quilombolas como sujeitos de direito, protagonistas de suas histórias e agentes sociais criativos, capazes de participar ativamente dos projetos e das propostas de desenvolvimento sustentável nas suas próprias comunidades.

$\mathrm{Na}$ arena de disputa entre projetos de desenvolvimento, onde os modelos hegemônicos se apresentam como universais e tentam anular outras possibilidades, o fortalecimento das estratégias territorializadas, comunitárias e verdadeiramente sustentáveis apresenta-se como uma real possibilidade. Conservação ambiental, fortalecimento da cidadania, valorização dos saberes, práticas e construção de relações sociais saudáveis e solidárias, são aspectos almejados pelas comunidades tradicionais e constituem possibilidades para partir de modelos de desenvolvimento que valorizem a diversidade. Nesse sentido, a ancestral cosmologia afro-brasileira é fonte rica de saberes e fazeres indispensáveis ao fortalecimento das comunidades quilombolas.

Para além da preocupação com as gerações futuras, a construção de um modelo de desenvolvimento "afro-sustentável", para as comunidades quilombolas, amplia o olhar para formas de produção para além de bens materiais, que valorizem a contribuição dos saberes, práticas e modos de vida das gerações passadas, ressignificando as necessidades atuais, com o cuidado entre as pessoas e com o meio ambiente.

\section{Considerações finais}

A sobrevivência física e cultural das comunidades quilombolas frente à violência do sistema escravocrata e aos séculos de exclusão social teve como alguns dos elementos centrais a utilização equilibrada e simbiótica dos recursos naturais. Além disso, as relações sociais de cuidado mútuo entre os membros das comunidades produziram solidariedades na gestão dos recursos, riquezas e responsabilidades comunitárias imprescindíveis ao processo de resistência vivenciado ao longo dos séculos nas comunidades espalhadas no Brasil.

O reconhecimento do racismo como fator determinante das concepções, estereótipos, injustiças e violação de direitos humanos e constitucionais no Brasil é etapa primordial para a redução das iniquidades raciais. Combater o racismo em suas mais variadas facetas, configuradas como barreiras ao processo de desenvolvimento das comunidades quilombolas, principalmente o racismo epistêmico, ambiental e institucional, torna-se etapa indispensável na agenda de desenvolvimento sustentável para as comunidades quilombolas.

A complexidade inerente ao mundo real requer um pensamento complexo capaz de superar a superficialidade e a fragmentação do problema e das ações. Nesse sentido, a busca por aportes teórico-metodológicos descolonizadores, que promovam o protagonismo afro-brasileiro, a partilha entre diferentes saberes e a emancipação dos atores sociais, é determinante para êxito de projetos de desenvolvimento efetivos e socialmente comprometidos com a melhoria da qualidade de vida dos sujeitos envolvidos. 
O fortalecimento do protagonismo das comunidades é capaz de promover enfrentamento contra as tentativas de destruição dos territórios tradicionais. A construção de modos de produção equilibrados ecológica, social e culturalmente são estratégias de resistência e conservação dos territórios que permitiram a sobrevivência da cultura afro-brasileira, bem como dos recursos naturais nas comunidades quilombolas.

O reconhecimento das demandas por educação, moradia, saúde, saneamento básico, e, principalmente, pela titulação dos territórios é condição primordial para pensar o desenvolvimento das comunidades quilombolas. Fora dessa perspectiva é impossível pensar na aplicabilidade de modelos econômica e ecologicamente viáveis dentro de comunidades marcadas pelo atraso na efetivação de direitos sociais e condições de vida digna.

A construção de um país socialmente justo, economicamente viável e ecologicamente equilibrado perpassa pela equitativa distribuição dos direitos, responsabilidades e riquezas. Os saberes e fazeres quilombolas orientados pela cosmovisão afro-brasileira demonstram caminhos e possibilidades de construção de relações saudáveis, solidárias e sustentáveis de vida, em harmonia com a natureza e com as pessoas.

\section{Referências}

ABA - Associação Brasileira de Antropologia. Documento do Grupo de Trabalho Sobre Comunidades Negras Rurais, Rio de Janeiro, 1994, p. 81-82. Disponível em: http://www. abant.org.br/?code=2.39 . Acesso em nov. 2014.

Alves, M. C.; Jesus, J. P.; Schols, D. Paradigma da afrocentricidade e uma nova concepção de humanidade em saúde coletiva: reflexões sobre a relação entre saúde mental e racismo. Saúde em Debate, 39(106), 2015. Disponível em: http://www.scielo.br/pdf/sdeb/v39n106/0103-1104-sdeb-39-106-00869.pdf

Anjos, R. S. A. Quilombos - geografia africana-cartografia étnica-territórios tradicionais. Brasília. Mapas editora \& consultoria, 2009.

Asante, M. K. Afrocentricity: The Theory of Social Change, Buffalo: Amulefi Publishing Company, 1980.

Asante, M. K. The Afrocentric Idea. Philadelphia: Temple University Press, Revised and Expanded $2^{\text {nd }}$ Edition, 1998.

Asante, M. K. Afrocentricidade: notas sobre uma posição disciplinar. In: Nascimento, E. L. (Org.). Afrocentricidade: uma abordagem epistemológica inovadora. São Paulo: Selo Negro, 2009. p. 93-110.

Bauman, Z. Comunidade: a busca por segurança no mundo atual. Rio de Janeiro: Zahar, 2003.

Bourdieu, P. A Dominação Masculina. Rio de Janeiro: Editora Bertrand Brasil, 2003, p 64.

Brasil. Constituição (1988). Constituição da República Federativa do Brasil. Brasília, DF: Senado Federal: Centro Gráfico, 1988. 292 p

Brasil. Ministério do Meio Ambiente. Biodiversidade Brasileira: Avaliação e Identificação de Áreas e Ações Prioritárias para a Conservação, Utilização Sustentável e Repartição dos Benefícios da Biodiversidade nos Biomas Brasileiros. Brasília. 404p. - 2002.

Brasil. Decreto $\mathrm{n}^{\circ} 6.040$, de 7 de fevereiro de 2007. Institui a Política Nacional de Desenvolvimento Sustentável dos Povos e Comunidades Tradicionais. Brasília, 2007.

Breilh, J. Epidemiologia Crítica: ciência emancipadora e interculturalidade. Rio de Janeiro. Editora Fiocruz, 2006.

Bruseke, F. J. O problema do desenvolvimento sustentável. In: Cavalcante, C. Desenvolvimento e Natureza: Estudos para uma sociedade sustentável. 5.ed. São Paulo: Cortez, 2009.

Carril, L. Quilombo, favela e periferia: A longa busca da cidadania. São Paulo: Annblume. FAPESP, 2006.

Carvalho, E. A. Saberes Culturais e educação para o futu- 
ro. In: Trindade, A. L. (Org.). Africanidades brasileiras e educação. [livro eletrônico]: Salto para o Futuro. Rio de Janeiro: ACERP; Brasília: TV Escola, 2013. Disponível em: http://cdnbi.tvescola.org.br/resources/VMSResources/ contents/document/publicationsSeries/1426109893818.pdf

Diegues, A. C. O mito da natureza intocada. Editora Hucitec, 2001.

Diegues, A. C. Sociedades e comunidades sustentáveis. São Paulo: USP/NUPAUB, 2003.

Ferreira. E. A 'Carta da Escrava Esperança Garcia do Piauí', Escrita por ela mesma, e sua relação com a poesia das mulheres dos Cadernos Negros. In: Barbosa, M.; Esmeralda, R. (Orgs.). Cadernos Negros: três décadas: ensaios, poemas, contos. São Paulo: Quilombhoje: Secretaria Especial de Políticas de Promoção da Igualdade Racial, 2008.

Finch III, C. S.; Nascimento, E. L. Abordagem afrocentrada, história e evolução. In: Nascimento, E. L. (Org.). Afrocentricidade: uma abordagem epistemológica inovadora. São Paulo: Selo Negro, p. 111-128, 2009.

Foucault, M. Em defesa da sociedade: curso no College de France (1975-1976). São Paulo: Martins Fontes, 1999.

Grosfoguel, R. La descolonización de la economía-política y los estudios poscoloniales: transmodernidad, pensamiento fronterizo y colonialidad global. In: Tábula Rasa (Bogotá, Colombia), nº 4 (enero-junio), pp. 17-48. 2006.

Grosfroguel, R. Dilemas dos Estudos Étnicos Norte-Americanos: Multiculturalismo identitário, colonização disciplinar e Epistemologias Descoloniais. Ciência e Cultura, 59(2). 2007. Disponível em: http://cienciaecultura.bvs.br/scielo. php?pid=S0009-67252007000200015\&script=sci_arttext

Henriques, A.; Porto, F. M. S. Território, ecologia política e justiça ambiental: o caso da produção de alumínio no Brasil. e-cadernos ces, 17, 2012. Disponível em: https:// eces.revues.org/1109.

Herculano, S. Lá como cá: conflito, injustiça e racismo ambiental. In: I Seminário Cearense contra o Racismo ambiental. Fortaleza: novembro de 2006 (mimeo).

Jevons, S. A teoria da economia política. Tradução de: Morais, C. São Paulo: Abril Cultural, 1983 [1871]. (Coleção os Economistas).
Kaphagawini, D. N.; Malherbe, J. G. African epistemology. In: Coetzee, P. H.; Roux, A. P. J. (Eds.). The African Philosophy Reader. New York: Routledge, p. 219-229, 2002.

Karenga, M. Afrocentricity and multicultural education. In: Mazama, A. (Org.). The afrocentric paradigm. Trenton, N.J: Africa World Press, 73-94, 2003.

Lacerda, R. S.; Silva, G. M. Reterritorialização, conflitos ambientais e saúde em comunidades quilombolas de Sergipe. Revista da ABPN, 8(18), 239-254, 2016. Disponível em: http://www.abpn.org.br/Revista/index.php/edicoes/ article/download/549/509

Layrargues, P. P. Do ecodesenvolvimento ao desenvolvimento sustentável: evolução de um conceito? Proposta, 25(71), 5-10, 1997.

Leff, E. Complexidade, Interdisciplinaridade e Saber Ambiental. In: Philippi Jr, A. Interdisciplinaridade em Ciências Ambientais. São Paulo: Signus, 2000.

Leff, E. Saber ambiental: sustentabilidade, racionalidade, complexidade, poder.

Petrópolis/RJ: Ed. Vozes, 2001.

Leite, F. Valores civilizatórios em sociedades negro-africanas. África: Revista do Centro de Estudos Africanos, 19-19(1), 103-118, 1996.

Lima, G. C. O discurso da sustentabilidade e suas implicações para a educação. Ambiente \& Sociedade, VI(2), 2003. Disponível em: http://www.scielo.br/scielo.php?script=sci_arttext\&pid=S1414-753X2003000300007

Lopes, N. Bantos, índios, ancestralidade e Meio ambiente. In: Nascimento, E. M. Guerreiras da natureza: mulher negra, religiosidade e ambiente. São Paulo, Selo Negro, 2008.

Mazama, A. A afrocentricidade como um paradigma. In: Nascimento, E. L. (Org.). Afrocentricidade: uma abordagem epistemológica inovadora. São Paulo: Selo Negro, 111-128, 2009.

Meadows, D. L.; Randers, J.; Behrens III, W. W. The limits to growth. A report for The Club of Rome's on predicament of mankind. Universe books, New York, 1972.

Melo G. P. (Eco)Turismo: uma (re)leitura dos discursos. Brasília: MMA, IBAMA, 2003. (Série Educação Ambiental). 
Morin, E. Ciência com consciência. Rio de Janeiro: Bertrand Brasil, 2002.

Morin, E. A cabeça bem feita: repensar a reforma, reformar o pensamento. Rio de Janeiro: Bertrand Brasil, 2003.

Morin, E. Introdução ao pensamento complexo. Porto Alegre: Sulina, 2009.

Moura, G. Salto para o Futuro: Educação Quilombola. Proposta pedagógica. Boletim 10. Junho de 2007.

Nascimento, E. L. O olhar afrocentrado: Introdução a uma abordagem polêmica. In: Nascimento, E. L. (Org.). Afrocentricidade: uma abordagem epistemológica inovadora. São Paulo: Selo Negro, 111-128, 2009.

Ramose, M. B. A ética do ubuntu. Tradução para uso didático de: Ramose, M. B. The ethics of ubuntu. In: Coetzee, P. H.; Roux, A. P. J.(Eds.). The African Philosophy Reader. New York: Routledge, 2002, p. 324-330, por Éder Carvalho Wen.

Rocha, R. M. C. A pedagogia da tradição: as dimensões do ensinar e do aprender no cotidiano das comunidades afro-brasileiras. Paidéia, 8(11), 31-52, 2011. Disponível: http://www.fumec.br/revistas/paideia/article/view/1308

Rodrigues, V. Programa Brasil Quilombola: Um Ensaio sobre a Política Pública de Promoção da Igualdade Racial para Comunidades de Quilombos. Cadernos Gestão Pública e Cidadania, 15(57), 2010.
Rodriguez, J. M. M.; Silva, E. V. Educação Ambiental e Desenvolvimento Sustentável: Problemática, Tendências e Desafios, Edições UFC, Fortaleza, 2013.

Sachs, I. Estratégias de transição para o século XXI. In: Bursztyn, M. Para Pensar o Desenvolvimento Sustentável. São Paulo: Brasiliense, 29-56, 1993.

Santos, L. C. F. Filosofia de raiz africana como um pensamento da complementaridade. Revista África e Africanidades, 2(8), 2010.

Santos, B. S. Um discurso sobre as ciências. São Paulo: Cortez, 2003

Santos. M. Por uma outra globalização: do pensamento único à consciência universal. Rio de Janeiro: Record, 2000.

Santos. M. O retorno do território. In: OSAL: Observatório Social de América Latina. Año 6 no. 16 (jun.2005). Buenos Aires: CLACSO, 2005.

Vieira, L. Santé, Espace social et Pratiques. Montreal: Departement d'Administration de la Santé, Université de Montréal, 1999. 